\title{
Endovascular Repair of an Infected Broken Pseudoaneurysm of the Extracranial Internal Carotid Artery
}

\author{
Claude Michel $^{1}$, Alain Parot ${ }^{2}$, Patrick Jue Denis ${ }^{2}$, Pierre-Yves Laffy ${ }^{1}$, Jean-Yves Riou ${ }^{3}$, Gilbert Leblanc ${ }^{1}$ \\ ${ }^{1}$ Vascular Radiology Department, Europe Medico-Surgical Center, Le Port Marly, France \\ ${ }^{2}$ Vascular Surgery Department, Europe Medico-Surgical Center, Le Port Marly, France \\ ${ }^{3}$ Cardio-Vascular Radiology Department, Marie Lannelongue Hospital, Paris, France \\ Email: C.Michel20@wanadoo.fr
}

Received September 18, 2012; revised October 19, 2012; accepted October 29, 2012

\begin{abstract}
The formation of pseudoaneurysms after carotid endarterectomy is extremely rare. Treating those pseudoaneuryms is necessary because of the risks for continued expansion, rupture and distal embolism. Traditional surgical repair of carotid artery pseudoaneurysms is associated with a high morbidity and mortality. An endovascular approach to these infected pseudoaneurysms limits the risk for operative damage to surrounding structures and potential blood loss.
\end{abstract}

Keywords: Carotid Artery; Pseudoaneurysm; Covered Self Expandable Stent

\section{Introduction}

The pseudoaneurysm of the internal carotid artery in its extracranial segment is among the rare diagnoses $[1,2]$ that must systematically be envisaged when faced with a pulsating mass in the cervical area or more rarely in the tonsil area [3]. The variability of the symptomatology makes this diagnosis difficult. Traditionally, the treatment is of a surgical nature [4,5]. In this paper, we report a case of infected pseudoaneurysm of the internal carotid artery apparently looking like an abscess on the lateral part of the pharynx. Based on existing reports and on this particular case, this paper describes the approach to this pathology.

\section{Case Report}

A 72-year-old patient arriving from Kinshasa was admitted in the nephrology department because of a kidney insufficiency. He had a past medical history of arterial hypertension, diabetes with an insulin dependence, a type $\mathrm{C}$ hepatitis and an endarterectomy of the left internal carotid artery with a widening Dacron patch.

When admitted in the department, he had a temperature of $40^{\circ} \mathrm{C}$ and a dysphagia, and a left laterocervical mass with a fistula located in the mid-segment of the scar of the endarterectomy. The physical neurologic examination was normal and there was no anomaly of the cranial nerves. The kidney insufficiency was significant with a blood area level of $1.96 \mathrm{gram} / \mathrm{L}$. Creatinemia was 101 $\mathrm{mg} / \mathrm{L}$, the alkaline reserve was $16 \mathrm{mmol} / \mathrm{L}$, an inflamematory syndrome with a VS of $94 \mathrm{~mm} / \mathrm{L}$ during the first hour and a CRP of $12 \mathrm{mg} / \mathrm{L}$. A dialysis catheter was installed in the right jugular vein while an antibiotic therapy was administered, using Vancomycine and Gentalline followed by Tienam Gentalline, given the presence of a Beta Lactonase with a wide spectrum (BLSE) in the sample of pus coming from the fistula. An infection of his endarterectomy Dacron patch was suspected. The left cervical ultrasound showed an irregular shaped mass adjacent to the internal carotid artery while the Power Doppler Ultrasound showed an ectasia with a blood flow in it. All this was compatible with a pseudoaneurysm. The damage was adjacent to the fistula. The thoracic cervical computed tomography showed that the left laterocervical mass was partly necrosed with a skin fistula including the carotid artery bifurcation and the sternocleidomastoid muscle with, within the mass, the partly thrombosed pseudoaneurysm of the internal carotid artery compressing the internal jugular vein (Figure 1). The arteriography of the supra-aortic trunks also showed the pseudoaneurysm of the internal carotid artery in its extracranial segment (Figure 2), a normal Willis polygon and no distal embolism in the left brain hemisphere. Following discussions within the medical staff, the decision was made to treat the pseudoaneurysm by an endovascular approach and the use of antibiotics. This was to be followed by a surgical debridement of the infected tissue and the excision of the Dacron patch. 


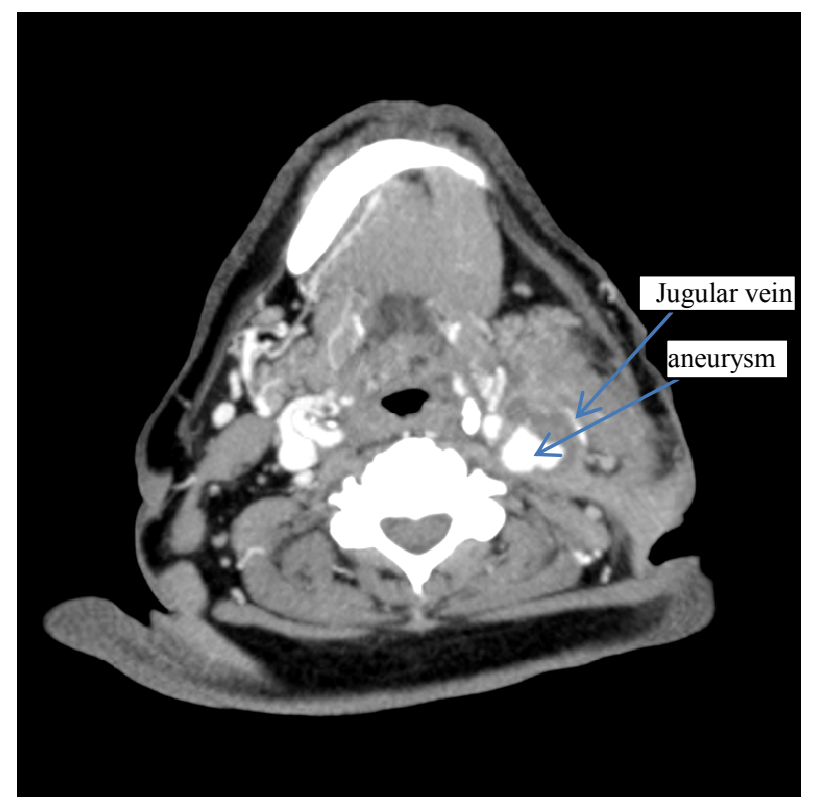

Figure 1. Preoperative computed tomography angiogram: Pseudo aneurysm of left internal carotid artery with surrounding infected tissues.

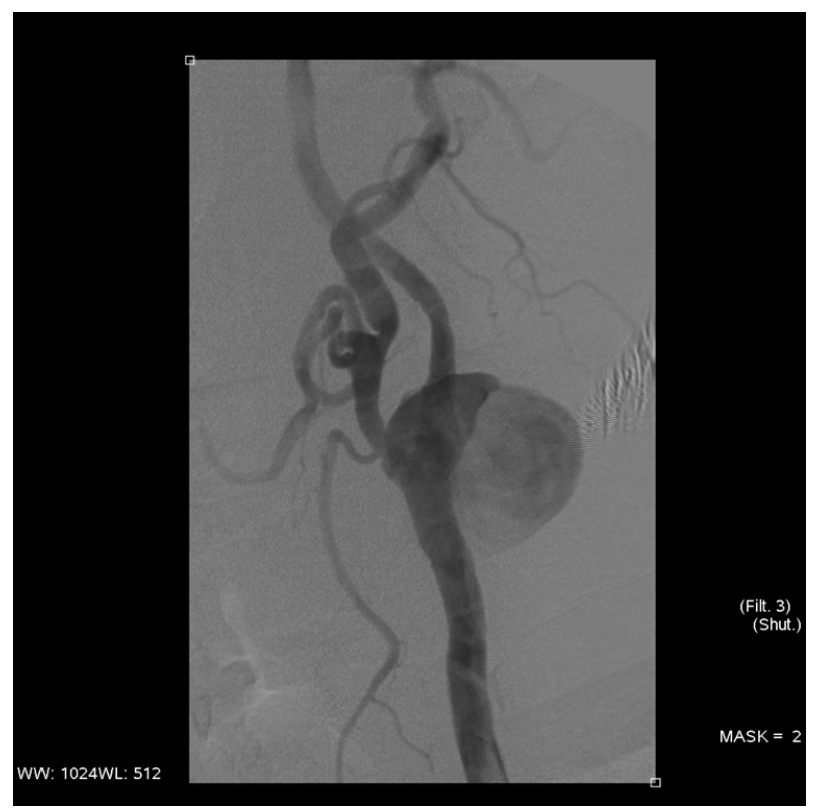

Figure 2. Selective angiography of the left internal carotid artery : Pseudoaneurysm at the bulb base.

The patient was premedicated with Clopidogrel 75 $\mathrm{mg} / 24 \mathrm{hr}$ and aspirin $100 \mathrm{mg}$ three days before the procedure (20/09/2011) which was to be conducted under local anesthesia. An 8F guiding catheter (Boston Scientific) was advanced in the left common carotid artery through a right femoral artery approach. A $5000 \mathrm{He}-$ parine units intraveinous bolus followed by a 1000 units/ hour perfusion was administered to keep the ACT $\geq 200$. A stiff AMPLATZ (Boston Scientific) guidewire was pushed beyond the aneurysmal neck until its end reached the mid-part of the left internal carotid artery. Subsequently, a $6 \times 36 \mathrm{~mm}$ PTFE covered graft stent Fluency (BARD) was advanced and deployed over the guidewire through the neck of the pseudoaneurysm. The angiographic control showed that the left carotid artery was leaking. The decision was then made to install another $7 \times$ $37 \mathrm{~mm}$ covered stent (FLUENCY) impacting in the mid-section of the first stent and opening out in the common carotid artery. The final angiographic control showed that the neck was closed without any opacification of the sac and also showed the occlusion of the external carotid artery (Figure 3). Beyond the aneurysm, the distal brain vascularization remained normal.

The patient was then transferred to the vascular surgical unit to excise the left cervical abscess. Following the pre-sternocleidomastoidal incision in the collection of pus, the pseudoaneurysm was found again in the form of a clot with a free PTFE patch, a part of the internal saphenous vein was taken and sutured on the previous arteriotomy so that the endoprotheses were covered and isolated from the infected lesions. The patient was then transferred to the intensive care unit to continue the antibiotic treatment with Tienam, Aspegic $250 \mathrm{mg} /$ day and a subcutaneous injection of Calciparine 0.3 three times a day. A few days later, he was discharged home from the Europe Medico Surgical Center and treated with Aspegic $100 \mathrm{mg} /$ day, Plavix $60 \mathrm{mg} /$ day for 6 months and Teradiene for 6 weeks. After 2 months, an ambulatory control was performed, consisting in a computed tomography

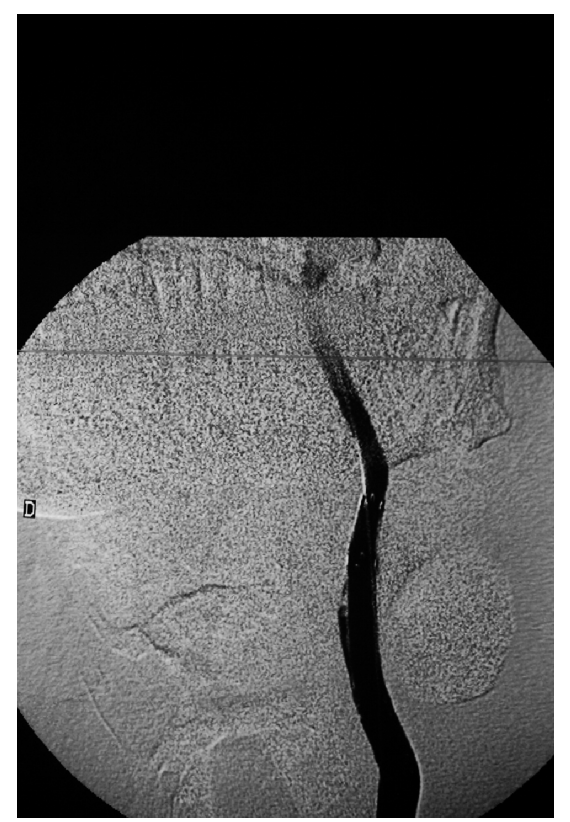

Figure 3. Angiogram of the left common carotid artery following deployment of self expandable covered stents fluency (Bard): Total exclusion of the pseudoaneurysm is observed. 
angiogram. It demonstrated the stability of the occlusion and the pseudoaneurysm without any evidence of stenosis (Figure 4). The patient was asymptomatic and had no neurological problem.

\section{Discussion}

Pseudoaneurysm formation is reported to occur after fewer than $1 \%$ of all CEAs [6]. The underlying factors that may lead to post-CEA pseudoaneurysm formation include suture line failure, deterioration of the patch or of the artery wall and infection [7]. Spontaneous evolutions are an increase in size, the appearance of thrombosis, an extrinsic compression, embolism causing cerebral ischemic events in more than $50 \%$ of the cases and a rupture generating a massive hemorrhage in $50 \%$ to $70 \%$ of the cases. The volume increase may cause dysphagia, neurological events on one side with a Claude Bernard Horner syndrome, paralysis of the cranial nerves (IX, X and XII) [8]. The traditional surgical treatment consists in an aneurysmectomy and a debridement of the infected tissues, excision of the patch which is replaced by a veinous or prothetic graft [9]. This procedure is complex $[10,11]$ because it means operating in infected areas modified by previous surgery. In addition, in function of the part of the carotid artery concerned and the size of the pseudoaneurysm, a proximal control of the carotid artery may demand a clavicular resection while the distal access may require a mandibular dislocation. The complete proximal and distal ligature of the carotid artery was recommended in the case of giant aneurysms with hemorrhages in order to save the patient's life [12]. The rate

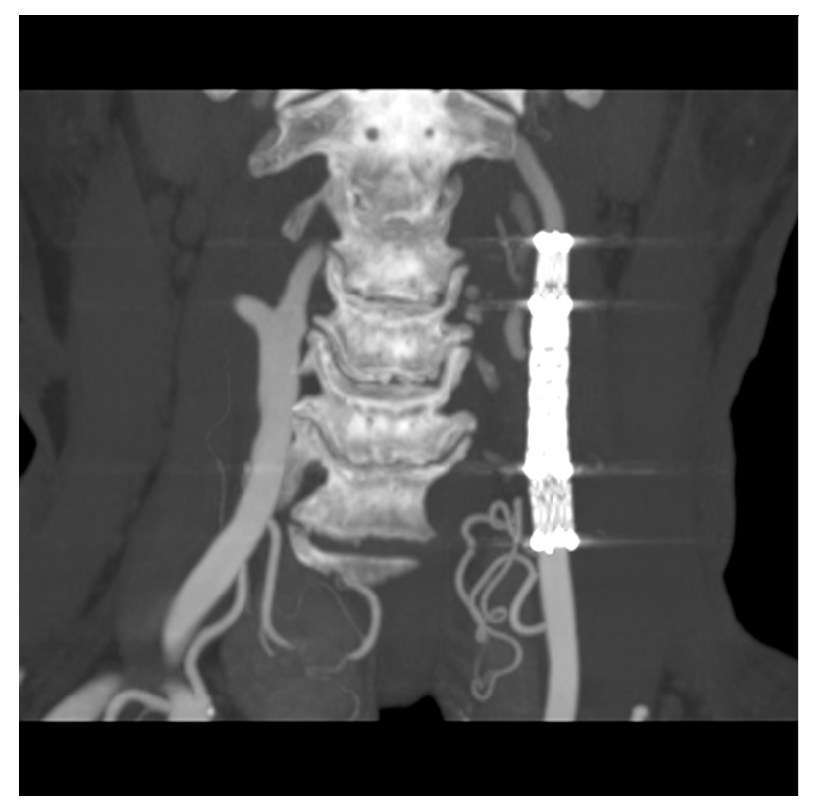

Figure 4. CTscan at 6 months follow-up showing persistant exclusion of the pseudoaneurysm and no stenosis of covered stents. of mortality and major neurological events is $10 \%$. Consequently, less aggressive endovascular techniques were recommended to avoid surgical complications. The selective embolisation procedure of the aneurysmal sac and the installation of metallic coils through the meshes of a stent was successfully achieved and preserved the permeability of the internal carotid artery while achieving a selective thrombosis of the aneurysmal sac [13]. This procedure presents a risk of rupture of the aneurysmal sac during the manipulation of the micro-catheter or of an incomplete occlusion of the pseudoaneurysm and the migration of thrombogenic material in the internal carotid artery. The percutaneous injection of Thrombine is contra-indicated in the case of infected pseudoaneurysms $[14,15]$. The endovascular use of endografts is attractive thanks to their capacity to isolate the aneurysm immediately while maintaining the carotid flow without resorting to general anesthesia [16-18]. However, the use of an endograft to treat pseudoaneurysms after an endarterectomy may be risky [19]. The possibility of an embolisation while passing the guidewire and during the installation of of the material must be taken into account [20], the more so as it turned out to be impossible to install an endoprothesis on a protective guide. In the present case, there was no filtering guidewire and the patient had no neurological events. A thrombosis of the endoprothesis may occur even if the patient is under anti-platelet therapy [21]. The patency of the external carotid was not the subject in account the risk of rupture. A possibility of restenosis always remains, particularly at the ends of the endoprothesis [22]. The long term durability of this kind of endovascular treatment still has to be determined [23]. An infection of the endoprothesis is always possible and demands repeated controls. A recurrent infection may justify - under antibiotherapy - an aneurysmectomy including the excision of the endoprothesis, the debridement of the infected tissues and an autogenous graft replacement and a carotid artery ligation with or without extra-anatomic bypass [24].

\section{Conclusion}

The standard treatment of infected aneurysms of the internal carotid artery is still the traditional open repair, consisting in an aneurysmectomy, debridement of the surrounding infected tissues and autogenous graft replacement, ligation of the carotid artery or extraanatomic bypass. However, in this particular case, the result indicates that the installation of a covered endoprothesis may be an effective option for the treatment of carotid artery pseudoaneurysms in the case of selected high risk patients to limit the risks for rupture, massive hemorrhage or embolisation. 


\section{REFERENCES}

[1] D. C. Schechter, "Cervical Carotid Aneurysms, Part I," New York State Journal of Medicine, Vol. 79, No. 6, 1979, pp. 892-901.

[2] Q. Zhang, Z. Q. Duan, S. J. Xin, X. W. Wang and Y. T. Dong, "Management of Extracranial Carotid Artery Aneuysms: 17 Years' Experience," European Journal of Vascular and Endovascular Surgery, Vol. 18, No. 2, 1999, pp. 162-165.

[3] G. L. Faggioli, A. Freyrie and A. Stella, "Extracranial Internal Carotid Artery Aneurysms: Results of a Surgical Series with Long-Term Follow-Up," Journal of Vascular Surgery, Vol. 23, No. 4, 1996, pp. 587-594. doi:10.1016/S0741-5214(96)80037-1

[4] E. Rosset, J. N. Albertini and P. E. Magnan, "Surgical Treatment of Extracranial Internal Carotid Artery Aneurysms," Journal of Vascular Surgery, Vol. 31, No. 4, 2000, pp. 713-723. doi:10.1067/mva.2000.104102

[5] C. D. Liapis, A. Gugulakis and E. Misiakos, "Surgical Treatment of Extracranial Carotid Aneurysms," International Journal of Angiology, Vol. 13, No. 4, 1994, pp. 290-295.

[6] C. L. Branch and C. H. Davis Jr., "False Aneurysm Complicating Carotid Endarterectomy," Neurosurgery, Vol. 19, No. 3, 1986, pp. 421-425.

doi:10.1227/00006123-198609000-00014

[7] C. A. Fernandez, S. Tagarro, C. G. Lozano-Arnilla, et al., "Internal Carotid Pseudoaneurysm within a Parapharygeal Infection: An Infrequent Complication of Difficult Diagnosis," Otolaryngology_Head and Neck Surgery, Vol. 132, No. 4, 2005, pp. 671-673. doi:10.1016/j.otohns.2004.09.025

[8] R. El-Sabrout and D. A. Cooley, "Extracranial Carotid Artery Aneurysms: Texas Heart Institute Experience," Journal of Vascular Surgery, Vol. 31, No. 4, 2000, pp. 702-712. doi:10.1067/mva.2000.104101

[9] R. El-Sabrout, G. Reul and D. A. Cooley, "Infected Postcaritid Endarterectomy Pseudoaneurysms: Retrospective Review of a Series," Annals of Vascular Surgery, Vol. 14, No. 3, 2000, pp. 239-247. doi:10.1007/s100169910041

[10] A. L. James, S. O’Malley and C. A. Milford, "Extracranial Internal Carotid Artery Aneurysm in a Child: A Diagnostic and a Surgical Challenge," The Journal of Laryngology \& Otology, Vol. 113, No. 4, 1999, pp. 373375. doi:10.1017/S0022215100144020

[11] T. Skau, J. Hillman, H. Harder and B. Magnuson, "Surgical Treatment of a Distal, Extracranial, Internal Carotid Artery Aneurysm Involving the Base of the Skull-A Multidisciplinary Approach," European Journal of Vascular and Endovascular Surgery, Vol. 20, No. 3, 2000, pp. 308-311. doi:10.1053/ejvs.2000.1108

[12] S. Tanaka, Y. Kimura and M. Furukawa, "Pseudoaneurysm of the Carotid Artery with Haemorrhage into the Hypopharynx," The Journal of Laryngology \& Otology, Vol. 109, 1995, pp. 889-891. doi: $10.1017 / \mathrm{S} 0022215100131603$

[13] R. L. Bush, P. H. Lin, J. R. Laird, et al., "Endoluminal Stent Placement and Coil Embolization for the Management of Carotid Artery Pseudoaneurysms," Journal of
Endovascular Therapy, Vol. 8, No. 1, 2001, pp. 53-61. doi:10.1583/1545-1550(2001)008<0053:ESPACE $>2.0 . C$ $\underline{\mathrm{O} ; 2}$

[14] M. J. Perez-Cruet, R. V. Patwardhan, M. E. Mawad and J. E. Rose, "Treatment of Dissecting Pseudoaneurysm of the Cervical Internal Carotid Artery Using a Wall Stent and Detachable Coils: Case Report," Neurosurgery, Vol. 40, No. 3, 1997, pp. 622-625.

[15] R. Holder, D. Hilton, J. Martin, et al., "Percutaneous Thrombin Injection of Carotid Artery Pseudoaneurysm," Journal of Endovascular Therapy, Vol. 9, No. 1, 2002, pp. 25-28.

doi:10.1583/1545-1550(2002)009<0025:PTIOCA $>2.0 . C$ $\mathrm{O} ; 2$

[16] K. F. Layton, Y. W. Kim and J. H. Hise, "Use of Covered Stent Grafts in the Extracranial Carotid Artery: Report of Three Patients with Follow-Up between 8 and 42 Months," American Journal of Neuroradiology, Vol. 25, No. 10, 2004, pp. 1760-1763.

[17] D. T. Baril, S. H. Ellozy, A. Carroccio, A. B. Patel, R. A. Lookstein and M. L. Marin, "Endovascular Repair of an Infected Carotid Artery Pseudoaneurysm," Vol. 40, No. 5, 2004, pp. 1024-1027. doi:10.1016/j.jvs.2004.08.019

[18] D. A. Troutman, C. R. Mohan, F. A. S amhouri and R. L. Sohn, "Endovascular Repair of Carotid Artery Pseudoaneurysm after Carotid Endarterectomy with Self-Ex- panding Covered Stents-A Long-Term Follow Up," Annals of Vascular Surgery, Vol. 24, No. 7, 2010, pp. 954.e13-16.

[19] J. May, G. H. White, R. Waugh and J. Brennan, "Endoluminal Repair of Internal Carotid Artery Aneurysm: A Feasible but Hazardous Procedure," Journal of Vascular Surgery, Vol. 26, No. 6, 1997, pp. 1055-1060. doi:10.1016/S0741-5214(97)70020-X

[20] Y. Kadkhodayan, C. P. Derdeyn, D. T. Cross and C. J. Moran, "Procedure Complicatios of Carotid Angioplasty and Stent Placement without Cerebral Protection Devices," Neurosurgical Focus, Vol. 18, No. 4, 2005, pp. 1-7. doi:10.3171/foc.2005.18.1.2

[21] D. L. Bhatt, S. R. Kapadia, C. T. Bajzer, et al., "Dual Antiplatelet Therapy with Clopidogrel and Aspirin after Carotid Artery Stenting," Journal of Invasive Cardiology, Vol. 13, No. 12, 2001, pp. 767-771.

[22] B. K. Lal, R. W. Hobson 2nd and J. Goldstein, et al., "In-Stent Recurrent Stenosis after Carotid Artery Stenting: Life Table Analysis and Clinical Relevance," Journal of Vascular Surgery, Vol. 38, No. 6, 2003, pp. 1162-1168. doi:10.1016/j.jvs.2003.08.021

[23] I. Saatci, H. S. Cekirge, M. H. Ozturk, et al., "Treatment of Internal Carotid Artery Aneurysms with a Covered Stent: Experience in 24 Patients with Mid-Term Results," American Journal of Neuroradiology, Vol. 25, No. 10, 2004, pp. 1742-1749.

[24] K. Hosoda, S. Fujita, T. Kawaguchi, Y. Shibata and N. Tamaki, "The Use of an Extracranial-Internal Shunt in the Treatment of Extracranial Internal Carotid Artery Saccular Aneurysms: Technical Case Report," Surgical Neurology, Vol. 52, No. 2, 1999, pp. 153-155. doi:10.1016/S0090-3019(99)00039-7 